\title{
MARCO TEMPORAL DAS POLÍTICAS DE EDUCAÇÃO DE JOVENS E ADULTOS EM MOÇAMBIQUE: PERSPECTIVAS DE FORMAÇÃO E OS ASPECTOS SOCIOECONÔMICOS
}

\section{Félix Matias ${ }^{1}$ Cláudia Araújo de Lima ${ }^{2}$}

${ }^{1}$ Licenciado em Educação de Adultos com Habilitação em Educação e Desenvolvimento Comunitário pela Universidade Pedagógica de Nampula Moçambique. Professor/Formador de Professores no IFPN. Estudante do PPGE Educação Social na UFMS/CPAN, pesquisador do NEPI/ Pantanal.

E-mal: felixmatiasney@gmail.com

${ }^{2}$ Pedagoga. Especialista em Processos Educacionais na Saúde com ênfase em Tecnologias. Mestre e Doutora em Saúde Pública. Professora da UFMS/CPAN no curso de Pedagogia e no PPGE - Área de Concentração: Educação Social. Coordenadora e Pesquisadora do Núcleo de Estudos e Pesquisas Interdisciplinares em Políticas Públicas, Direitos Humanos, Gênero, Vulnerabilidades e Violências NEPI/ Pantanal.

\section{Recebido em: 15/05/2021 - Aprovado em: 15/06/2021 - Publicado em: 30/06/2021 DOI: 10.18677/EnciBio_2021B13}

\begin{abstract}
RESUMO
O presente artigo teve por objetivo refletir sobre os marcos temporais que vem influenciando nas políticas de alfabetização e educação de jovens e adultos (EJA) concebidas e implementadas em Moçambique. Partindo da concepção históricofilosófica, efetua-se uma discussão relativa às políticas da EJA que ao longo dos tempos vêm sendo concebidas, de modo a compreender a razão da sua concepção, tendo em conta o contexto e os desafios de cada momento; ou seja, procura-se entender, o que tem influenciado a concepção das políticas e das estratégias de EJA no País, e com que visão ou referência básica pedagógica e social se baseia a concepção das políticas educativas moçambicanas? Com estas indagações teve-se como objetivos específicos: identificar as grandes etapas que marcam o percurso da EJA e de todo um sistema nacional de ensino em Moçambique; analisar a contribuição de Paulo Freire na concepção e implementação das políticas públicas de educação no País; e descrever alguns fatores que influenciam no insucesso das políticas educativas implementadas. O estudo concluiu que, por um lado, a trajetória da EJA em Moçambique pode ser entendida através de três etapas, e por outro, o percurso de todo o sistema nacional de educação no País pode ser compreendido a partir de dois períodos distintos nomeadamente, a educação antes da independência e a educação pós-independência. Conclui-se também que a visão de Freire sobre a educação tem sido fundamental na concepção das políticas da EJA; Percebeu-se ainda que os aspectos socioeconômicos têm influenciado significativamente nas políticas educativas.
\end{abstract}

PALAVRAS-CHAVE: Educação de Jovens e Adultos em Moçambique. Marco temporal. Políticas de Educação. 


\title{
TEMPORAL FRAMEWORK FOR YOUTH AND ADULT EDUCATION POLICIES INMOZAMBIQUE: TRAINING PERSEPECTIVES AND SOCIOECONOMIC ASPECTS
}

\begin{abstract}
The presented article has an objective to reflect on the time frames that have been influencing youth and adult literacy and education (EJA) politics designed and implemented in Mozambique. Starting from the historical-philosophical conception, there is a discussion regarding the politics of EJA that over the years has been conceived, in order to understand the reason for its conception, taking into account the context and challenges of each moment; that is, we seek to understand, what has influenced the design of EJA politics and strategies in the country, and with what basic pedagogical and social vision or reference is the conception of Mozambican educational policies based? With these inquiries, the specific objectives are: to identify the major stages that mark the course of EJA and of an entire national education system in Mozambique; analyze the contribution of Paulo Freire in the design and implementation of public education politics in the country; and describe some factors that influence the failure of the implemented educational politics. The study concluded that, on the one hand, the trajectory of EJA in Mozambique can be understood through three stages, and on the other hand, the trajectory of the entire national education system in the country can be understood from two distinct periods namely, the pre-independence education and post-independence education. It is also concluded that Freire's view on education has been fundamental in the design of EJA policies; It was also noticed that socioeconomic aspects have significantly influenced the educational politics designed and implemented in the country.
\end{abstract}

KEYWORDS: Education policies.0'9' "Time frame. Youth and Adult Education in '«Mozambique.

\section{INTRODUÇÃO}

Atualmente com uma população de aproximadamente 30 milhões, e uma extensão territorial de $801.590 \mathrm{Km}^{2}$, Moçambique é um País Africano que alcançou recentemente a sua independência nacional, isto é, em 1975, dos colonos Portugueses que ficaram no território mais de 500 anos. Desde a independência nacional até aos dias de hoje o País tem vindo a conceber e implementar várias políticas de educação, incluindo a alfabetização e educação de jovens e adultos, que é considerado um dos subsistemas do sistema nacional de educação. A complexidade dos processos educativos, aliado a sua diversidade de abordagem, constituem aspectos que impõem a necessidade de refletir de forma permanente, de modo a compreender os fatores que influenciam nas políticas públicas de educação, desde a sua concepção até a implementação (QUIMUENHE, 2018).

No que diz respeito à educação moçambicana, importa referir que, o País ao perceber que só com um povo educado se pode alcançar um desenvolvimento social, cultural e econômico, adotou mecanismos que pudessem levar a combater os índices do analfabetismo que eram elevadíssimos. Para isso, vem implementando diversos programas de alfabetização e educação de adultos, dentro das suas políticas de educação. Essas políticas nem sempre tiveram a mesma característica, muito menos uma evolução linear, os vários acontecimentos históricos foram influenciando o percurso da educação, e da EJA em particular. São esses momentos que este artigo chama de marcos temporais das políticas de educação (INTANQUÉ; SUBUHANA, 2018). 
É importante referir que não são somente os acontecimentos ocorridos no País que vem influenciando as políticas de educação, mas também as políticas dos organismos internacionais vêm interferindo de forma significativa nas ações e políticas públicas locais, o que torna Moçambique um País vulnerável na definição de estratégias, aliado ao fator pobreza, que é o mais determinante, pois, os países financiadores dos orçamentos e das iniciativas de âmbito social apresentam seus condicionamentos, interferindo assim de forma direta nas políticas públicas, o que nem sempre é benéfico na realidade local. Uma concepção de políticas de EJA onde se espelha uma visão crítico-reflexiva, assume o compromisso de permitir que o indivíduo seja emancipador, exerça a cidadania e desenvolva uma consciência que Ihe conduza a uma de liberdade e transformação social (MECHISSO, 2020).

O presente artigo propõe uma reflexão sobre os marcos temporais das políticas de educação de jovens e adultos (EJA) em Moçambique, sua perspectiva de formação e a influência dos aspectos socioeconômicos nas políticas de educação.

Este artigo resultou de um estudo de caráter qualitativo, quando se faz uma reflexão sobre os marcos temporais das políticas de EJA em Moçambique. A escolha desta modalidade de pesquisa, prende-se ao fato da pesquisa qualitativa permitir uma análise não baseada nos dados estatísticos, e ainda preocupar-se com o processo, como refere Oliveira (2011). Quanto aos objetivos, efetuou-se um estudo descritivo, cuja fonte de coleta de dados foi análise documental. Portanto, o referencial teórico que ajudou na discussão dos resultados deste estudo é Paulo Freire, um pensador brasileiro de referência mundial no que concerne aos processos de educação de jovens e adultos. Por outro lado, os documentos do Ministério de Educação e Desenvolvimento Humano de Moçambique (MINEDH) e da Direção Nacional de Alfabetização e Educação de Adultos (DINAEA) permitiram o aprofundamento de alguns aspectos que marcam a trajetória da EJA no País.

Cinco fases caracterizaram este estudo, sendo que, na primeira, identificou-se alguns descritores dentro do tema; a segunda fase foi marcada por um processo de busca das obras publicadas, nos diferentes bancos de dados virtuais (estado de arte); a terceira fase foi de leitura e seleção das publicações com vista a encontrar aquelas que mais se aproximam ao objeto deste estudo; a quarta fase foi de categorização, a quinta e última o tratamento/discussão dos dados. De referir que o processo de análise e interpretação dos dados foi efetuado na base da análise do conteúdo sugerida por Bardin (2011). A escolha destes procedimentos metodológicos deveu-se pelo tipo do problema e os objetivos que se pretendia alcançar. Trata-se de uma revisão bibliográfica efetuada na primeira quinzena do Mês de Maio, no ano de 2021, no Brasil, com uma reflexão sobre a realidade de educação moçambicana.

\section{EDUCAÇÃO DE JOVENS E ADULTOS EM MOÇAMBIQUE, UM PERCURSO DESAFIADOR}

A trajetória da alfabetização e educação de jovens e adultos em Moçambique pode ser entendida a partir de três etapas distintas, que marcam a concepção e a implementação das políticas desta área. A independência nacional proclamada em 1975 marca o início da primeira etapa da EJA no País, que se estende até a metade da década 80. Nesse período, o ponto referencial é a consagração da Educação de adultos como um pilar do Sistema Nacional de Educação -SNE (CASTIANO et al., 2005). 
Destaca Nandja (2006, p.2), que esta etapa foi caracterizada por um processo dinâmico e multifacetado de mobilização popular para as ações de reconstrução nacional, de construção da unidade nacional e de afirmação da identidade moçambicana. Desta forma, várias ações foram levadas a cabo, das quais destacam-se:

A realização de sucessivas campanhas de alfabetização e educação de adultos em todo o território nacional. - A realização de um conjunto de ações planejadas e concertadas de educação e formação de adultos junto de determinadas empresas, comunidades ou setores sociais definidos como "estratégicos" para o desenvolvimento socioeconômico do país pelo governo foram desencadeadas (...) (NANDJA, 2006, p.2).

É importante referir que a primeira campanha nacional de alfabetização foi lançada em 1978, por Samora Moisés Machel, o então Presidente da República, sob - lema "façamos do País inteiro uma escola onde todos aprendemos e todos ensinamos" (MINEDH, 2016). Considera-se esta campanha como sendo a primeira ação no campo da educação no período pós-independência nacional. Na sequência, mais três campanhas de alfabetização forma lançadas, sendo que a partir de 1980 as campanhas de alfabetização foram interligadas às campanhas de educação de adultos que tinham como finalidade assegurar a continuação do processo de aprendizagem até o nível que correspondia a $4^{\underline{a}}$ Classe do ensino geral em vigor (SEFANE, 2018, p.146).

De acordo com o mesmo autor, dentro das campanhas, havia dois processos educativos distintos, olhando pelas especificidades do grupo alvo, sendo: campanhas de alfabetização, que eram mais elementares e que destinavam-se aos iniciantes e ia até ao nível equivalente a 2ª Classe; já a campanha de educação de adultos, era destinada para as pessoas que tendo terminado a fase de alfabetização, ou tendo um nível equivalente a $2^{-}$Classe, quisessem dar continuidade com os seus estudos, estes iam até a $4^{\text {a }}$ Classe do ensino vigente. (SEFANE, 2018).

A duração de cada um dos dois processos educativos era de nove meses, ou seja, tanto as campanhas de alfabetização quanto a de duração de adultos o período de duração era o mesmo. Entre 1978 a 1982, decorria ainda três modalidades de educação de adultos como: os cursos de formação acelerada de trabalhadores, os cursos noturnos da $5^{\mathrm{a}}$ a $9^{\mathrm{a}}$ Classe e os cursos noturnos do Ensino Primário (NANDJA, 2006 p. 58). Os Centros de Formação Acelerada de Trabalhadores (CFAT's), foram criados em 1978, sendo que em cada Província havia pelo menos um centro. Estes centros tinham como objetivo, preparar os quadros e trabalhadores de vanguarda dos setores sociais e econômicos considerados prioritários, para que estes pudessem responder aos desafios, uma vez que havia pouca mão-de-obra. Nesses centros, as aulas eram ministradas num regime acelerado, num período de seis meses, os participantes eram obrigados a viverem no internato, cuja 4⿳亠丷a Classe era o nível de ingresso (NANDJA, 2006).

Como resultado dessas ações, tornou-se possível dentro de cinco anos a redução significativa da elevada taxa do analfabetismo no seio da população adulta, de $97 \%$ em 1974 para $72 \%$ em 1982, ou seja, reduzida em $25 \%$, em relação ao índice herdado da proclamação da independência. Foi ao longo deste período, isto é, em 1976 que se criou a Direção Nacional de Alfabetização e Educação de Adultos, com a responsabilidade de gerir tudo que tinha a ver com os processos de alfabetização de adultos (NANDJA, 2006). 
É importante salientar que apesar de alguns avanços nem tudo corria como devia ser. As atividades tanto nas campanhas de alfabetização quanto nas campanhas de educação de adultos, foram caracterizadas por diversas dificuldades. Como indica o estudo do Instituto Nacional de Desenvolvimento de Educação INDE, em relação ao decurso das atividades nessa época, constatou-se que a grande maioria das dificuldades relacionavam-se com às condições materiais, dificuldades em relação aos próprios agentes envolvidos no processo de ensinoaprendizagem e dificuldades do próprio processo de ensino-aprendizagem (INDE/MINED 1999).

Relativamente às condições existentes, o INDE/MINED (1999) aponta para a deficiência no funcionamento dos Serviços Distritais de Educação de Adultos que haviam sido criados para o apoio pedagógico e para organização das campanhas, dada insuficiência dos recursos humanos e materiais capazes de responder a demanda. No caso dos recursos humanos, os quadros preparados não conseguiam fazer a cobertura, na medida em que a procura era maior e os poucos existentes tinham que se desdobrar para tentar cobrir a diversas tarefas, o que tornava a qualidade cada vez mais baixa, para além do cumprimento das metas que era cada vez mais impossível. Alia-se a este fato, a problemática das próprias condições de trabalho que também foram deficitárias, comprometendo de forma significativa o cumprimento dos objetivos.

Um dos aspectos que marca a política de EJA em Moçambique ao longo da primeira etapa do percurso é a introdução em 1983, do Subsistema de Educação de Adultos (SSEA), como componente do Sistema Nacional de Educação (SNE), cuja finalidade era garantir que a população maior de 15 anos tivesse oportunidade de se formar cientificamente, isto envolvia vários graus e níveis oferecidos pelo Subsistema de Educação Geral vigentes. Dentre outros objetivos do subsistema, destacam-se:

1) Assegurar o acesso da população trabalhadora à educação, com prioridade para a classe operária, camponeses cooperativistas e camadas sociais com papel fundamental no processo político, econômico, social e cultural da sociedade socialista; 2) Proporcionar uma formação científica geral que confira os conhecimentos, capacidades e atitudes necessárias para aquisição de uma concepção científica materialista do desenvolvimento da natureza, da sociedade e do pensamento, criando as condições para a superação da mentalidade obscurantista; 3) Desenvolver a consciência patriótica e revolucionária do Homem Novo (SNE LEI 4/83 Artigo. 21).

O referido subsistema de educação de adultos foi criado dentro da Lei 4/83, do Sistema Nacional de Educação, que é a primeira lei concebida no País após a independência nacional. Este instrumento constitui uma das grandes referências que influenciou o percurso subsequente da educação moçambicana (CASTIANO et al., 2005).

A segunda etapa da trajetória da EJA em Moçambique, teve seu início na metade da década 80 tendo se estendido até 1995. Esta foi uma época cuja característica principal era a redução significativa das ações de alfabetização e educação de adultos por motivos da intensificação da guerra de desestabilização em Moçambique, influenciada pelo regime do "Apartheid" da República Sul Africana. Com o decorrer da guerra, muitas vidas humanas foram perdidas, milhares de moçambicanos viram-se obrigados a refugiarem-se em países vizinhos, milhões de deslocados em todo País, várias infraestruturas destruídas (SEFANE, 2018).

Desta forma, parte significativa das pessoas passou a residir nas cidades à procura de segurança, e foi nas grandes cidades onde algumas ações da EJA ENCICLOPÉDIA BIOSFERA, Centro Científico Conhecer - Jandaia-GO, v.18 n.36; p. 173 
passaram a ter lugar. Somente as organizações não-governamentais (ONGs), as confissões religiosas e algumas pessoas de forma individual é que garantiram a continuação de programas em escala menor, e esses na maioria tentaram inovar os programas, concebendo ações de alfabetização por meio de línguas locais, como forma de responder as limitações do momento (INDE/MINED, 1999).

Um outro aspecto que marcou esta época foi a extinção em 1990, da Direção Nacional de Educação de Adultos (DNEA), que havia sido criada em 1976, com a finalidade de orientar e controlar o sistema de alfabetização e educação de adultos, excluindo a formação profissional. Com a extinção desta direção, todas as ações que lhe eram incumbidas assim como os recursos humanos passaram a integraremse na Direção Nacional do Ensino Básico, num departamento designado por "Departamento de Alfabetização e Educação de Adultos - DAEA" (MÁRIO; NANDJA, 2005 , p. 11). Dada necessidade de tornar os processos educativos mais abrangentes, foi introduzido em 1991 o Programa de Alfabetização em Línguas Moçambicanas, com destaque para as línguas: Sena, Ndau, Changana, Emakua, Nyandja, uma ação enquadrada no Projeto de Educação Bilingue de Mulheres. No ano seguinte, isto é, em 1992 foi aprovada a Lei $n^{\circ}$ 6/92 que atualiza o SNE, revogando assim a Lei 4/84. Com a então nova lei, a educação de adultos ficou definida como uma modalidade especial do ensino escolar, organizado para indivíduos que já não se encontram na idade normal de frequência dos ensinos geral e técnico-profissional (Art.31). E ainda este instrumento define o ensino extraescolar como sendo aquele que integra ações de alfabetização e de aperfeiçoamento e atualização cultural e científica, realizando-se num ambiente fora do sistema regular de ensino (CASTIANO; NGOENHA, 2013).

Como forma de garantir a formação de quadros desta área, criou-se em 1992, um Instituto Nacional de Educação de Adultos (INEA), na Beira, Província de Sofala, centro do País, uma instituição vocacionada para a formação de profissionais da área de educação de adultos (EA), para além de desenvolver pesquisas, documentação e informação e fazer assistência técnico-pedagógica das ações de EA (MÁRIO;NANDJA, 2005). No ano seguinte criou-se um curso de Bacharelato em Educação de Adultos, numa ação coordenada entre a Universidade Pedagógica (Moçambique) e Likoping (Suécia), inicialmente com 24 estudantes. De referir que este curso não viu garantida a sua continuidade, tendo logo terminado (NANDJA, 2006).

Já a terceira etapa do percurso da EJA em Moçambique iniciou-se em 1995 e vai até aos dias de hoje. Este período é marcado pela conquista da paz, estabilidade social, fruto da reconciliação nacional, elementos importantes que aliviaram parte significativa das grandes limitações das etapas anteriores através do desenvolvimento econômico e social dos próprios moçambicanos. Esta fase pode ser caracterizada por dois processos, um de retomada e resgate da alfabetização e educação de adultos (positiva), outra a desaceleração significativa de várias ações desta modalidade (negativa), apesar de nesta etapa o setor ter atingido um nível satisfatórios em termos de recursos humanos assim como materiais, com a formação de vários quadros e a implementação de diversos programas de EJA, tanto por iniciativa do setor público quanto do setor privado através das organizações não-governamentais (INTANQUÊ;SUBUHANA, 2018).

Entre os marcos desta etapa pode-se destacar: a recriação da Direção Nacional de Alfabetização e Educação de Adultos no Ministério da Educação, no ano de 2000, esta que havia sido extinta a 10 anos anteriores; a concepção do Plano de Ação para a Redução da Pobreza Absoluta (PARPA). A redução da taxa 
do analfabetismo era apontada como uma das prioridades das políticas públicas do governo moçambicano; aprovação pelo Conselho de Ministros, da estratégia do subsetor de alfabetização e educação de adultos e educação não formal (20012005), com a finalidade de aumentar o acesso à população jovem e adulta com vista a reduzir no mínimo em 10\% a taxa do analfabetismo; a introdução em 2001 do Programa de Mestrado em Educação de Adultos, na Universidade Eduardo Mondlane (UEM), Faculdade de Educação, com o intuito de formar profissionais para responder às necessidades da sociedade moçambicana no que concerne à formação de formadores para o desenvolvimento comunitário rural e/ou urbano, à profissionalização de adultos no mercado de trabalho através de um vínculo efetivo entre a teoria e a prática laboral e à formação de profissionais das áreas de alfabetização e pós-alfabetização de adultos (NANDJA 2006, p.9). À essas ações marcantes nesta etapa, juntam-se também a extinção do Instituto Nacional de Formação de Educadores de Adultos (INEA), que era único no País, dando lugar a criação dos Institutos de Formação de Educadores de Adultos (IFEAs), que mais tarde viriam a ser também extintos em 2015 (MATARUCA, 2021).

As políticas dos organismos internacionais para a área de educação contribuíram muito na definição de estratégias que culminaram com a concepção e implementação de vários programas. Isso pode estar influenciado com o fato dos recursos financeiros para a EJA dependerem de apoio externo, pois a dado momento, com a redução dos apoios financeiros desacelerou também a intensidade que caracterizava as ações deste subsistema, ou seja, vários programas foram terminando, apesar de não ter sido erradicado o analfabetismo na totalidade (FARIA; 2020).

Atualmente, apesar da existência de vários quadros formados nessa área, os programas de EJA são desenvolvidos com uma certa limitação, e ainda, as aulas são ministradas, na maioria, por alfabetizadores voluntários, sem formação psicopedagógica, os quais são contratados anualmente, num número que também vem reduzindo a cada ano, fazendo com que diversas comunidades não tenham abrangência dos programas de EJA. Para além do fato dos programas enfrentarem o velho problema de insuficiência dos próprios materiais didáticos, que inclui os livros e manuais. Isto faz com que os alfabetizadores/educadores enfrentem sérias dificuldades em termos de condições de trabalho, sem contar com o próprio incentivo em termos da remuneração que nem chega a um terço do salário mínimo moçambicano. Estes e outros problemas contribuem para a ineficácia e a desaceleração das ações de EJA no período em curso (SEFANE, 2018).

Esta trajetória de educação de jovens e adultos em Moçambique tem muita relação com a história da própria educação moçambicana. A educação no País é vista como um processo que vista preparar o homem para melhor se inserir na sociedade. Trata-se de um processo conduzido para o alcance de certos objetivos, que com o passar do tempo podem variar, mediante os anseios da sociedade, dentro dos desafios que o contexto impõe; aliás, essa é a parte dinâmica dos objetivos de qualquer processo; tenta-se sempre enquadrar naquilo que se almeja a curto, médio ou longo prazo. Refletindo a volta da história de educação em Moçambique, percebe-se que esta nem sempre teve a mesma característica, e que a Independência Nacional em 1975 é considerada como um ponto referencial (SAPANE, 2014). Portanto, de acordo com Castiano et al., (2005), dois grandes períodos podem caracterizar o processo de educação em Moçambique, nomeadamente: período antes da Independência e período pós-Independência. 
A Educação em Moçambique no período antes da Independência: este período pode ser dividido em duas etapas que marcam a história que são: a) a educação no período colonial e b) a educação no governo de transição. Na primeira etapa deste período, ou seja, a educação no período colonial vai de 1845 a 1974, e teve como característica principal a dominação, alienação e cristianização da educação. Com a dominação do colono, que estava vivendo uma Monarquia em Portugal, criou uma regulamentação do ensino nas suas colónias, a 02 de Abril de 1845, tendo adotado em Agosto desse mesmo ano, um decreto que estabelecia diferenças entre o ensino nas colónias e na Metrópole para além de criar escolas públicas nas colónias (CASTIANO et al., 2005).

Nos anos subsequentes foram criados e publicados diversos instrumentos de políticas educativas coloniais, que culminaram com a instituição de várias escolas primárias, sendo que as primeiras foram implantadas na llha de Moçambique, no Ibo, em Quelimane, Sena, Inhambane e Lourenço Marques (Hoje Maputo, a capital moçambicana). Dentre os vários instrumentos legislativos da educação colonial dessa etapa, destaca-se o de 30 de Novembro de 1869, que reformava o Ensino Ultramar, o qual tornava obrigatório o ensino primário, e dividia este ensino em dois graus, com duas classes cada, sendo que as escolas encontravam-se tuteladas pelas missões católicas. A primeira escola secundária em Moçambique foi instituída em 1912, na Cidade de Lourenço Marques (CASTIANO et al., 2005).

Um dos aspectos que marcou a educação colonial em Moçambique foi a existência de dois subsistemas de ensino, que são: 1) Ensino Oficial, que era destinado aos filhos dos colonos ou dos assimilados e; 2) Ensino rudimentar, adotado para os ditos "indígenas" que eram os nativos, colonizados. Significa que, na era colonial em Moçambique o sistema de ensino tinha duas modalidades, com duas perspectivas de formação distintas, sendo uma para a classe dominante ou a elite que tinha $o$ ensino oficial, que era mais privilegiado, e eram transmitidos conhecimentos que conduziam a construção de valores aristocráticos. E a outra para modalidade que era dirigido ao povo indígena ou colonizado, com a perspectiva de formação resumia-se simplesmente ao ensino da leitura e escrita e atividades domésticas. Destarte, o sistema de educação nesse período era totalmente discriminatório (CASTIANO et al., 2005).

Já na segunda etapa desse primeiro período que vai de 1974 a 1975, e corresponde a educação no Governo de Transição é uma etapa que segundo Castiano et al., (2005), resulta das ocorrências indicadas nos anos anteriores, como é o caso da fundação em 1962, de um movimento político denominado FRELIMO (Frente de Libertação de Moçambique), uma organização política que desencadeou a luta de libertação nacional, que culminou com a assinatura dos Acordos de Luzaka em 1974, e que deu lugar ao surgimento do Governo de Transição (GOMEZ, 1999). O reconhecimento deste período como uma das etapas importantes tem a ver com o fato de que as grandes mudanças na área de educação ao nível nacional resultam das ações e experiências vividas pela FRELIMO, sobretudo o modelo ou tipo de sociedade que almejava dentro dos parâmetros desenhados em decorrência da Luta Armada contra o colonialismo português. Portanto, este movimento político, introduziu um tipo de educação na qual a escola era do povo, ou seja, a escola devia atender as causas e os interesses do povo. Tratava-se então de uma educação com a perspectiva política e ideológica, que se pretendia entre outros aspectos, revolucionar o ensino (GOMEZ, 1999).

A educação moçambicana no período pós-Independência: este período teve seu início em 1975 com a conquista da Independência Nacional e também pode ser 
subdividido em duas etapas, dadas grandes reformas que a educação foi sofrendo, visando a preparação do povo moçambicano para adequar ao contexto sociopolítico, econômico e cultural. Estas etapas são: a) educação moçambicana pósIndependência-I, b) educação moçambicana pós-Independência-II. Constituem marcos principais deste período a criação de três Leis do Sistema Nacional de Educação (SNE), nomeadamente: a Lei 4/83(SNE 1983) ; a Lei 6/92 (SNE, 1992); e a Lei 18/2018 ( SNE 2018) (ZIMBICO, 2019).

$\mathrm{Na}$ primeira etapa deste período, que inicia em 1975 vai até 1990, nos anos antes do surgimento do SNE (1975-1982) foram marcados pela nacionalização da educação a 24 de Julho de 1975, o que originou a suspensão de todas as formas do sistema do ensino colonial português; a proclamação do direito à educação para todos os moçambicanos, pela Constituição da República Popular de Moçambique (20 de Junho de 1975) e a consequente massificação do acesso à educação em todos os níveis de ensino; a introdução de um currículo educacional transitório do sistema colonial português para o nacional (1975); a criação dos centros de formação de professores primários e a consequente abolição das instituições portuguesas vocacionadas à formação de professores (CASTIANO et al., 2005).

Com a Independência Nacional, portanto, o povo estava eufórico, mas quatro anos depois compreende que tinha mais desafios do que soluções. E para responder a esses desafios, foi adotada uma política educacional nas zonas libertadas, onde priorizava a alfabetização e educação de adultos, a educação formal e formação de professores. Portanto, a EJA tornou-se a base, num momento em que o eixo definido foi educação - trabalho - formação. Influenciaram a educação nessa época: questões demográficas - o País vasto mas com pouca gente; baixo nível de alfabetização; e o sistema marxista leninista (socialismo) que vigorava. É importante referir que quando se adotou a lei 4/83 do SNE, Moçambique estava em guerra de desestabilização que iniciou em 1976 até 1992 com assinatura dos acordos em Roma (ASSANE et al., 2017).

A segunda etapa do período de educação na era pós-Independência, teve início nos anos $90 \mathrm{com}$ a mudança do sistema socialista para o capitalista. A expansão desse contexto neoliberal influenciou na mudança radical da Constituição da República de Moçambique, que impactou na mudança dos setores sociais. O País adotou então, um novo contexto de educação para adequar ao novo sistema mas com influência dos organismos internacionais. Isso resultou na aprovação da nova lei do SNE, a lei 6/92 (CASTIANO et al., 2005).

As conferências internacionais de educação sempre tiveram uma repercussão na educação moçambicana, como se pode observar, após conferência de Jomtien (1990) que declarou a educação pata todos, condicionou a revisão da lei 4/83 para o surgimento da lei 6/92 que vigorou desde 1992 até 2018; a conferência internacional de Takar (2000) que definiu a educação do novo milênio fez com que o governo moçambicano definisse de ano em ano os planos quinquenais e os planos estratégicos de educação; após a conferência internacional de Incheon de 2015 que definiu a educação inclusiva e equitativa de qualidade, com vista a promover oportunidades de aprendizagem ao longo da vida para todos, influenciou na revisão da lei do SNE com aprovação da lei 18/2018 atualmente em vigor, onde faz menção a questão da inclusão escolar (FARIA, 2020).

Todo este histórico da educação moçambicana vem influenciando nas políticas da EJA e sobretudo nos programas implementados nesta área, que apesar de alguns avanços, há também muitos desafios que desfavorecem o processo de ensino e aprendizagem dos jovens e adultos através dos programas desta 
modalidade, sendo que maior parte destes desafios estão mais relacionados com as próprias políticas públicas educacionais. Como se pode observar, a trajetória da EJA tem uma grande semelhança, senão ligação, com a trajetória de todo o sistema de educação em Moçambique. Os eventos que marcam a história do País no âmbito social, econômico e político, têm uma influência direta nas políticas e estratégias

Até hoje inequívoca a contribuição de Paulo Freire na educação de Jovens e adultos em Moçambique e no mundo. O contato de Freire com a áfrica, ocorre num período em que vários países deste continente encontravam-se em via de conquistar sua independência nacional, contexto esse que Freire considerou como oportuno para a transmissão da sua experiência através de uma visão pedagógica que permitisse a preparação dos povos colonizados, com vista à atingir uma autonomia no pensamento crítico. Os pressupostos teóricos e práticos que Freire incluía na sua pedagogia político-libertadora, foram como uma "luz no fundo do túnel", dada possibilidade de ler e escrever que proporcionava aos povos, para além da pertinência que dá para estes refletirem sobre a sua história, marcada por humilhações do colono (SCHWENGBER;CHICAVA, 2019).

De acordo com estes autores Schwengber e Chicava (2019), as contribuições de Paulo Freire continuam sendo uma "marca indelével" na concepção de políticas públicas educacionais, em vários países do continente africano incluindo Moçambique. É inegável que a colonização dos países africanos trouxe consigo alguns benefícios com a civilização ocidental, mas também foram várias consequências que desta resultaram, e ficou evidente a inferiorização dos povos colonizados, o que influenciou na educação, como afirma Freire (1978), a educação se caracterizou pela atitude de subordinação, mantendo o mito da superioridade do branco, ou seja, ocorreu a "desafricanização dos nacionais". Para manter a inferiorização dos povos, na educação eram transmitidos valores culturais portugueses, desvalorizando os saberes locais. Sem mencionar ainda que o próprio acesso a educação que era desigual, discriminatório na base do status social e racial que fez com que houvesse dois tipos de educação, sendo um para a classe dominante e outro para os chamados indígenas, estes que lhes era proporcionada uma educação mais rudimentar com uma visão muito limitada para não abrir sua mente.

Ao longo dos tempos, a língua de ensino também tem sido mais uma barreira na EJA em Moçambique, já que as pessoas são obrigadas a usarem o português que é uma língua do ocidente, em detrimento da sua própria língua. Nisso há que concordar com o pensamento de Freire, ao afirmar que as políticas educativas coloniais obrigaram o indígena a esquecer de sua própria condição africana através de uma pedagogia alienante: "a criação de uma consciência hospedeira da opressão" (FREIRE, 1983, p. 71).

Proclamada a independência nacional de Moçambique em 25 de Junho de 1975, que naturalmente, originou a formação de um novo Governo, houve a necessidade de nacionalização dos setores sociais, em particular o da educação. Importando referir que, o País herdou dos colonos um índice elevadíssimo do analfabetismo, que era de $93 \%$, pelo que urgiu a necessidade de desenvolver diversas ações e práticas educativas que pudessem a curto ou médio prazo reduzir esta cifra (MAZULA, 1995).

A história recente de opressão colonial, que ficou marcado na memória dos moçambicanos, obrigou a que tivesse que se pensar num tipo de educação que pudesse desenvolver capacidades de análise crítica do contexto vivido. Era necessário promover uma reconstrução nacional. Nisso, os pensamentos de Paulo 
Freire (1978) e de Machel (1979) acabaram sendo as grandes referências das políticas de educação que o País adotou, dada visão de considerar os povos oprimidos como potenciais detentores do poder capaz de transformar a sua história, pelo que a educação era a única chave para desbloquear a cultura de passividade, e que só com a educação libertadora e transformadora é que seria possível fazer com que o povo pudesse exercer a cidadania e participar na transformação da sociedade.

A educação como um instrumento de intervenção social na visão de freire: uma das contribuições de Freire que marca a EJA é de considerá-la como uma ferramenta indispensável para a intervenção na sociedade. Freire defende nos seus escritos a educação como sendo um ato político, capaz de libertar os sujeitos da situação de opressão, levando-os a uma conscientização em relação a si mesmo e ao mundo que os rodeia. Este pensamento Freire veio a aprofundar na sua obra "Pedagogia do Oprimido", com apresentação da essência das suas ideias em relação ao papel da educação, quando destaca a grande vantagem de se adotar uma educação voltada aos jovens e adultos. Esta acaba sendo uma das maneiras de Freire (1999) apresentar de forma clara a sua crítica às práticas educativas desenvolvidas nesse período (FREIRE, 1999).

Nesta ordem de ideias, Freire deixou evidente a sua intenção de adotar por um tipo de educação que chamou de "Educação Libertadora", a qual, na sua perspectiva, a escola tem a função de auxiliar o aluno, no sentido deste descobrir a si mesmo e se tornar sujeito da sua própria história. Para isso, a educação teria que alterar as suas práticas pedagógicas que se caracterizavam num verdadeiro descarregamento dos conteúdos do professor ao aluno, passando então para práticas mais ativas, onde o aluno torna-se participativo, projetando-se formar um sujeito crítico, mais autónomo e capaz de transformar a realidade em que está inserido (FREIRE, 2011).

As reflexões efetuadas por Freire transmitem uma necessidade preponderante de olhar a educação enquanto processo sem o qual torna difícil estabelecer a liberdade, isto é, as práticas pedagógicas implementadas devem garantir que os indivíduos oprimidos possam se libertar dos atos violentos dos seus opressores. Esta crítica surge num momento em que a maioria dos países africanos estavam sendo colonizados, mas em via de alcançar a sua independência. $E$ a educação oferecida era de total imposição da cultura estrangeira, desvalorizando os saberes dos povos locais. Por isso que o autor refere que "do ponto de visita dos interesses dominantes, não há dúvida de que a educação acaba sendo um conjunto de práticas imobilizadoras e ocultadoras de verdades" (FREIRE, 1996, p. 99).

Nessa perspectiva, compreende-se que ao definir as políticas de educação deve-se ter em conta a perspectiva de formação que se pretende para esse grupo alvo, pois, se a educação for um instrumento para intervenção na sociedade, esta deve construir mentes suficientemente preparadas para responder e transformar 0 mundo em que estiver inserido, ou seja, a educação a ser oferecida deve proporcionar ao indivíduo a capacidade de tomar atitudes que sejam benéficas tanto ao nível pessoal quanto coletivo. Neste caso, as políticas públicas de educação são determinantes, pois, num país onde se exercer domínio sobre o povo, a preocupação nunca será de implementar programas que possibilitam a autonomia do indivíduo ou grupo, muito menos uma educação que espelha a realidade vivida localmente. Simplesmente os educandos passam a receber um conjunto de conteúdos que não têm muita relação com o mundo real, fazendo do aluno um mero recipiente, que é aquilo de (FREIRE, 2011, p. 24) chamou de "educação bancária", 
onde o aluno não desenvolve o espírito crítico sustentável e capaz de transformar o mundo real. Uma educação bancária traduz-se na imposição do pensamento científico, resultando na alienação da ignorância, instrumentalização e opressão do indivíduo, que toma a posição de objeto no lugar de ser o sujeito do seu processo de aprendizagem. A adaptação das práticas educativas como instrumento transformador e uma ferramenta para a intervenção na sociedade, surge como necessidade de desenvolver nas pessoas o poder e a autonomia de autossuperação dos problemas que vem registrando ao longo da sua história e nas relações do diaa-dia. Pelo contrário, a educação bancária não só impõe a memorização dos conteúdos, como também desenvolve uma cultura de passividade no aluno, o que resulta na falta de participação na tomada de decisões para o bem-estar comum (FREIRE, 2009).

$\mathrm{Na}$ medida em que o educando apropria-se na reflexão de si próprio e do mundo que lhe rodeia, descobre que afinal ele é capaz de participar de forma ativa na construção e transformação da sociedade em que vive e na construção e transformação da sua própria história. Nisso, ao educador cabe-lhe a responsabilidade de promover ações pedagógicas que despertem no educando a cultura de reflexão sobre o mundo e suas relações. Um ato que passa pela problematização dos fenômenos no qual Freire (2002), considera o desenvolvimento de atitude de criticidade como sendo um dos pontos mais relevantes para educação libertadora e transformadora. A transformação da realidade ocorre na medida em que o indivíduo ganha consciência da sua condição de existência, e a consciência da opressão ou exploração a que os indivíduos estão permanentemente submetidos. Quanto mais o sujeito tiver consciência de sua condição de dominação e exploração social, mais condições de intervir terá para inverter a situação (FREIRE, 2002).

Geralmente os educandos da EJA vão aos estudos acreditando que a escola representa uma via concreta e objetiva de garantir por si a inclusão social (FREIRE, 2000). Portanto, é importante para isso a valorização daquilo que o educando trás consigo como parte do seu conhecimento, sem fugir da linhas de pensamento científico; o que impõe maior responsabilidade no que ao papel do educador diz respeito. Isso vai ao encontro do raciocínio de Freire (2011), que considera que "ao se relacionar o educador e o educando é necessário ter o cuidado de reconhecer sua inconclusão enquanto seres humanos, uma consciência que faz com que estes intervenientes do processo educativo tenham a capacidade de aprender, e não simplesmente visando a adaptar-se, mas principalmente reconstruir o real contexto.

Pensar numa política de educação cuja perspectiva de formação seja mais adequada aos problemas reais das comunidades, não somente força as pessoas a adquirirem conhecimento, como também permite que esses conhecimentos sejam aplicados na vida prática. Há uma grande vantagem de conscientizar as pessoas de que seu nível de vida não depende apenas de sua capacidade de gerar valores financeiros, mas as qualidades adquiridas por meio dos recursos dentro da comunidade (FRANCO, 2016).

No quadro das políticas internacionais o analfabetismo é considerado uma ameaça ao desenvolvimento socioeconômico, ou seja, tudo voltado à questão econômica, ao neoliberalismo. Portanto, muitos governantes estão mais preocupados com a redução dos índices de analfabetismo, apenas por questões de estratégia política voltada para as campanhas eleitorais ou pelo fato do analfabetismo atrapalhar o crescimento econômico do país. Entretanto, a realidade mostra que nos últimos períodos a preocupação somente ocorre na teoria, porque na prática pouco se faz nesta érea. São evidentes as deficiências de políticas e 
estratégias voltadas para a EJA, o que é uma grande contrariedade, que coloca em causa o progresso das comunidades e o bem-estar social (CARDOZO et al., 2017).

É importante referir que o processo de alfabetização e educação de jovens e adultos é um desafio, não só para as entidades governamentais, universidades, professores, como também para toda a sociedade e sobretudo para o próprio educando/ aluno. Isto porque, mesmo que as politicas e os programas de EJA sejam muito bem concebidos, se não forem bem recebidos por parte dos beneficiários, haverá sempre erros na implementação e, descarte, nos seus resultados. A maioria das populações moçambicanas, por exemplo, não demonstram muito interesse aos programas da EJA, o que torna ainda mais deficitária a política desta modalidade de ensino (PIERRO, 2010).

O clássico pensador Freire (2003), tentou fazer perceber, o quão é importante valorizar o que cada ser humano consegue fazer, isto é, utilizar o conhecimento e a experiência que a pessoa traz ao longo de sua vida, sendo pertinente a criação de condições que ajudem a aumentar e atualizar seus conhecimentos, pois, cada um tem a sua história, e cada ser em si carrega o dom de ser capaz e ser feliz.

Ao falar da EJA em todas as etapas do seu percurso na sociedade moçambicana, há que lembrar as afirmações de Freire (1999, p.18) que diz:

a educação sozinha não transforma a sociedade, sem ela tampouco a sociedade muda. Se opção é progressista, se está se a favor da vida e não da morte, da equidade e não da injustiça, do direito e não do arbítrio, da convivência com o diferente e não de sua negação, não se tem outro caminho se não viver a opção que se escolheu. Encarná-la, diminuindo, assim, a distância entre o que se diz e o que se faz.

Nessa perspectiva, torna-se claro sobre o que se pode fazer para enfrentar os desafios que o mundo atual impõe, que certamente passa necessariamente pela definição de políticas claras e sustentáveis, principalmente para a área de educação, como forma de preparar o homem que seja capaz de lidar da melhor maneira com as demandas do dia-a-dia (SEVERINO, 2006). Naquilo que Heerdt e Coppi (2003, p. 69), chama de nova realidade escolar, considerando que o grande desafio, sem dúvida, não é o de estar ciente destas transformações, mas sim integrá-las e contemplá-las no trabalho educacional. Portando, essa integração e contemplação deve ser acompanhada de análise crítica das políticas públicas, para não incorrer no risco de conceber políticas internacionais que de certa forma não se enquadram na realidade local das comunidades.

Por outro lado, é importante que os programas de educação não sejam implementados apenas para cumprir com a agenda do governo, e sim olhando nos impactos que estes trazem na realidade para o bem-estar das pessoas, a curto, médio e longo prazo, mas também olhando as influências para as futuras gerações (MORIN, 20O2). É isso que Freire (2007) defende: uma educação progressista, em que o educador e o educando caminham juntos, e defende ainda uma educação transformadora.

A concepção das políticas educativas, portanto, deve possibilitar a construção de uma consciência crítica dos participantes envolvidos nos programas oferecidos, tornando o homem cada vez mais livre do pensamento, mais democrático, capaz de promover mundanças importantes nas suas relações tanto com a sociedade, como com o meio ambiente onde este se encontra inserido. Esse olhar crítico, seria o ponto essencial para uma mudança "urgente" defendido por Freire (2006) ao considerar que "mudar é difícil, mas é possível e urgente." (FREIRE, 2006). 
A mesma linha de pensamento afirma Gadotti (2000, p.23) que, "o que faz um jardim são os pensamentos do jardineiro." Com isso, o autor complementa assume a necessidade de "continuar defendendo o sonho e a utopia" com um comprometimento com as ideias da emancipação humana.

Atualmente, Moçambique conta com uma taxa do analfabetismo de $39 \%$, de acordo com CENSO (2017), cifra esta que vem sendo combatida desde que o país se tornou independente em 1975. São diversos fatores que concorrem para a persistência das taxas elevadas do analfabetismo no país, fatores esses que podem ser explicados pelo nível de pobreza do país, que influencia tanto nas condições do setor de educação, quanto nas próprias populações que, ao ter que escolher entre ir a escola e ir a machamba, a grande maioria preferem a machamba ou outras atividades braçais devido a falta de condições de sobrevivência (MINEDH, 2020). O distanciamento entre a teoria e a prática na educação escolar constitui também um dos aspectos que mina muitos programas educacionais e todo percurso da EJA em Moçambique, ou seja, as políticas podem até ser ambiciosas mas a sua prática é muito deficitária, o que não facilita o cumprimento dos objetivos e metas predefinidas, para além do reflexo deficiente dessas políticas na vida real das populações (NANDJA, 2006).

\section{CONSIDERAÇÕES FINAIS}

Os marcos temporais da educação de jovens e adultos em Moçambique ajudam a entender, por um lado, os acontecimentos históricos no âmbito socioeconômico que vem influenciando o sistema de educação como um todo e na EJA em particular, e por outro, a influência que Paulo Freire teve nas políticas públicas de educação que o país vem concebendo e implementando na área de educação de jovens e adultos.

Importa referir que, ao se espelhar de Paulo Freire na concepção das políticas de EJA em Moçambique, pretende-se responder o compromisso de educação para o bem-estar das comunidades; proporcionar processos de alfabetização tendo em conta a diversidade sociocultural e de género; e ainda desenvolver uma criatividade, inovação e uma capacidade de reflexão crítica, elementos importantes para uma transformação social. Os desafios da educação libertadora e transformadora podem ser respondidos através de um conjunto de práticas educativas que coloca o diálogo como uma ferramenta preponderante no processo de ensino e aprendizagem dos alunos. Nisso, o aluno deve ser o centro de todas as atenções da educação. Esta forma de pensar é característica de Paulo Freire, por isso que é evidente a sua contribuição nas políticas públicas de educação moçambicana e no mundo.

\section{REFERÊNCIAS}

ASSANE, A. I.; JULIASSE, A. C.; NTUNDUATHA. Escola como uma base para o povo tomar o poder? Diálogo entre Samora Machel e Paulo Freire. MovimentoRevista de Educação. Niterói, ano 4, n.7, p.209-227, jul./dez. 2017.

BARDIN, L; Análise de Conteúdo. s.ed. Tradução: Luís Antero Reto e Augusto Pinheiro. Lisboa: s/l, 2011.

CARDOZO, E.N.R.; MIRANDA, A.L.F.; SANTOS, M.S.; PESSOA, L.N.F. Educação e Neoliberalismo em contexto Brasilerio: Elementos Introdutórios à Discussão. Educare. s.ed. IV Seminário Internacional de Representacoes Sociais, Subjetividade e Educacao, ISSN 2176-1396. 2017. 
CASTIANO, J. NGOENHA, S.; BERTHOUD, G.; A longa marcha de uma educação para todos em Moçambique. Maputo: Imprensa Universitária, 2005.

CASTIANO, J. P.; NGOENHA, S. E.; A longa marcha duma "educação para todos" em Moçambique. Maputo: Publifix, 2013.

CENSO 2017. IV Recenseamento geral da População e m Moçambique. Instituto Nacional de Estatística. Maputo: INE. 2017.

FARIA, C. F. Políticas Públicas de Educação: Programa de Ensino Secundário a Distancia (PESD) em Moçambique. Revista África E Africanidades - Ano XIII, $\mathrm{n}^{\circ}$ 34. Maio. 2020. ISSN 1983-2354. Brasil. Acesso em 29 e Maio 2021. Disponível em: http://africaeafricanidades.online $>0110052020$

FRANCO, M. A. R. S.; Prática pedagógica e docencia: um olhar a partir da epistemologia do conceito. Revista brasileira de Estudos pedagogicos (on-line), Brasília, v. 97, n. 247, p. 534-551, set./dez. 2016. Acesso em: 10 de Maio de 2021, Disponivel em: https://doi.org/10.1590/S2176-6681/288236353

FREIRE, P. Educação como prática da liberdade. 14. ed. Rio de Janeiro: Paz e Terra, 1983.

FREIRE, P. Pedagogia do oprimido. 17. ed. Rio de Janeiro: Paz \& Terra, 1978.

FREIRE, P. Pedagogia da autonomia: saberes necessários à prática educativa. 36ª ed. São Paulo: Paz e Terra, 1996.

FREIRE, P. Pedagogia da Autonomia: saberes necessários à prática educativa. 12ª Ed. Rio de Janeiro: Paz e Terra, 1999.

FREIRE, P. Pedagogia da Indignação - carta Pedagógica e Outros Escritos. São Paulo: Unesp, 2000.

FREIRE, P. Educação para prática da liberdade. 26aㅡ ed. São Paulo: Paz e Terra, 2002.

FREIRE, P. Educação como Prática da Liberdade. Rio de Janeiro, Ed. Paz e Terra. $27^{\mathrm{a}}$ ed. 2003.

FREIRE, P. A importância do ato de ler: em três artigos que se completam. $48^{\mathrm{a}} \mathrm{ed}$. São Paulo: Cortez, 2006.

FREIRE, P. Educação e mudança. 30ª ed.; Rio de Janeiro: Paz e Terra, 2007.

FREIRE, P. Educação como prática da liberdade. Rio de Janeiro: Paz e Terra, 2009.

FREIRE, P. Pedagogia da Autonomia: saberes necessários à prática educativa. 43. ed. São Paulo: Paz e Terra, 2011. 
GADOTTI, M. Perspectivas atuais da educação. Porto Alegre, Ed. Artes Médicas, 2000.

GOMEZ, M. B.. Educação Moçambicana - História de um processo (1962-1984). Maputo: Livraria Universitária UEM. 1999.

HEERDT, M.L., COPPI. P. de. Como Educar Hoje? reflexões e propostas para uma educação integral. São Paulo : Mundo e Missão,2003. p. 34,69,70.

INDE/MINED. Plano Curricular do Ensino Básico: Objectivos, Estrutura, planos de Estudos e Estratégias de Implementação. Maputo: UNESCO, 1999.

INTANQUÊ, S. T.; SUBUHANA, C. Educação Pós-independência em Moçambique. Rev. África e Africanidades - Ano XI - n. 26, abr. 2018 - ISSN 19832354. Acesso: em 15 de Maio de 2021. Disponível em: http://africaeafricanidades.com.br > 0030260042018

MACHEL, S. M. Fazer da escola, uma base para o povo tomar o poder. Maputo: Departamento do ideológico da FRELIMO, 1979.

MÁRIO, M.; NANDJA, D. A alfabetização em Moçambique: desafios da educação para todos. s.ed. UCM, Maputo, 2005.

MATARUCA, I. V. M.. Percepções e expectativas dos formadores e formandos do Instituto De Formação de Professores de Chongoene. REVES - Revista Relações Sociais, Vol. 04 n. 02. 2021. Acesso em 30 de Maio de 2021. Disponivel em: https://doi.org/10.18540/revesvl4iss2pp12375-01-15e

MAZULA, B. Educação, cultura e ideologia em Moçambique: 1975-1985. Maputo: Fundo Bibliográfico da Língua Portuguesa: Edições Afrontamento, 1995. 247p.

MECHISSO, G. B. Influências das políticas globais na expansão do ensino superior em Moçambique. Revista Interritorial. UFPE. Brasil: 2020. Acesso: 12 de Abril de 2021. Disponível em: https://doi.org/10.33052/inter.v6i10.244913

MINEDH: Plano Estratégico de Educação (2016 - 2020). Moçambique, Maputo, 2016.

MINEDH: Plano Estratégico de Educação (2020 - 2029). Moçambique, Maputo, 2020.

MORIN, E.; A cabeça bem-feita. Repensar a reforma, reformar o pensamento. $7^{\text {a }}$.ed. Tradução de Eloá Jacobina. Rio de Janeiro: Bertrand Brasil, 2002.

NANDJA, D. Educação de adultos em Moçambique: uma cronologia de factos. S.ed. Moçambique: Universidade Eduardo Mondlane. Maputo: 2006.

OLIVEIRA, M. F. Metodologia científica: um manual para a realização de pesquisas em Administração / Maxwell Ferreira de Oliveira. -- Catalão: UFG, 2011. 
PIERRO, M. C. D. A educação de jovens e adultos no plano nacional de educação: avaliação, desafios e perspectivas. Educ. Soc., Campinas, v. 31, n. 112, p. 939959, jul.-set. 2010. Acesso em: 02 de Maio de 2021. Disponível em: http://www.cedes.unicamp.br

QUIMUENHE, A. História da Educação Moçambicana no seculo XX: Lei 4/83 e Lei 6/92 do Sistema Nacional de Educação. RCE, v.3, ISSN 2526-4257 e 019011. Brasil: 2018.

SAPANE, B.M.; A sociedade contemporânea e a configuração da educação moçambicana. Revista Vozes dos Vales: Publicações Acadêmicas Reg.:120.2.095-2011- UFVJM ISSN: 2238-6424. N ${ }^{\circ}$ 06. 2014. Acesso em 02 de Maio 2021. Disponível em: http://www.ufvjm.edu.br/vozes.

SCHWENGBER, I. L.; CHICAVA, A. K. A. Pedagogia de Paulo Freire na concepção da educação moçambicana. Revista Pedagógica, Chapecó, v. 21, p. 447-461, 2019. DOI: http://dx.doi.org/10.22196/rp.v22i0.4934

SEFANE, C. E. Impato dos Programas de Alfabetização e Educação de Adultos: Análise do papel da Alfabetização na vida docial dos Alfabetizandos em Moçambique, v.10, n. 21, UFAL, Brasil: 2018.

SEVERINO, A.. A busca do sentido de froamacao humana: tarefa da Filosofia da Educação. Revista Educação e Pesquisa, v.32, n.3, p. 619-634, São Paulo: 2006.

SNE - LEI no 4/83, de 23 de Março. Boletim da República. BR nº 12, I Série, 1983.

SNE - LEI n 6/92, de 6 de Maio. Boletim da República. BR nº 19, I Série, 1992.

SNE - LEI n 18/2018 de 28 de Dezembro. Boletim da República. BR $n^{0} 254$, I Série, 2018.

ZIMBICO, O. J. História, política e educacao: o novo modelo de escolarizacao primária em Mocambique. Educação, v. 42, n. 1, p. 67-76, 6 maio 2019. Acesso em: 10 de Maio de 2021. Disponível em: https://doi.org/10.15448/19812582.2019.1.28623 